Vol.2, No. 1, Jan. 2019

\title{
DEKOMPOSISI PERMASALAHAN DAN SOLUSI KEBIJAKAN PENGEMBANGAN LKMS BERBASIS GRAMEEN
}

\author{
Abdul Mughni*), Fiqih Afriadi \\ STEI Tazkia \\ Email : fiqih4fri4di@gmail.com
}

\begin{abstract}
The purpose of this study is to decompose the problems and policy solutions for the development of grameen-based Microfinance Institutions (MFIs). In its replication in Indonesia, this grameen-based MFI has undergone various modifications and adjustments. What is interesting is that most grameen-based MFIs that can continue to grow and be consistent in empowering the poor in Indonesia are the grameen sharia model (LKMS). Of course it is a useful thing to be able to find out how this can happen, but something more important than that is to find out how the strategies needed so that the effects in alleviating poverty can continue to be maintained and improved. There are many sides that can be explored to see the various causes that make this grameen-based LKMS able to continue to grow and be consistent in empowering the poor. One of them is on the side of the problem and the development policy solution. To describe the grameen-based LKMS liquidity policy problems, researchers used the ANPBOCR research methodology. ANP-BOCR methodology is a qualitative analysis research that seeks to capture the values or views represented by practitioners and experts through surveys, interviews, FGDs and literature studies as data sources for the preparation of the ANP model framework. We chose this methodology because of its compatibility with the formulation of the problem, it can produce priority levels of each policy and can also provide more complete information through in-depth interviews and FGDs with Experts and Practitioners. The object of this research is grameen-based LKMS which is spread in JABODETABEK.
\end{abstract}

Keywords : Grameen Syariah, LKMS, ANP DECOMPOSITION

\begin{abstract}
Abstrak
Tujuan dari penelitian ini adalah untuk melakukan dekomposisi permasalahan dan solusi kebijakan pengembangan Lembaga Keuangan Mikro (LKM) berbasis grameen. Dalam replikasinya di Indonesia LKM berbasis grameen ini mengalami berbagai modifikasi dan penyesuaian. Yang menjadi menarik adalah ternyata sebagian besar LKM berbasis grameen yang dapat terus bertumbuh dan konsisten dalam memberdayakan fakir miskin di Indonesia adalah model grameen syariah (LKMS). Tentu saja menjadi hal yang bermanfaat untuk dapat mengetahui bagaimana hal tersebut dapat terjadi, akan tetapi sesuatu yang
\end{abstract}


lebih penting dari itu adalah untuk mengetahui bagaimana strategi yang diperlukan agar efek dalam mengentaskan kemiskinan bisa terus dipertahankan dan di tingkatkan. Terdapat banyak sisi yang bisa di gali untuk melihat berbagai penyebab yang menjadikan LKMS berbasis grameen ini dapat terus bertumbuh dan konsisten dalam memberdayakan fakir miskin. Salah satunya adalah pada sisi permasalahan dan solusi kebijakan pengembangan. Untuk menguraikan permasalahan kebijakan likuiditas LKMS berbasis grameen ini, peneliti menggunakan metodologi penelitian ANP-BOCR. Metodologi ANP-BOCR merupakan penelitian analisis kualitatif yang berusaha untuk menangkap suatu nilai atau pandangan yang diwakili para praktisi dan pakar melalui Survei, wawancara, FGD dan studi literatur sebagai sumber data untuk penyusunan kerangka model ANP. Metodologi ini kami pilih karena kesesuaianya dengan rumusan permasalahan, dapat menghasilkan tingkatan prioritas dari masingmasing kebijakan dan juga dapat memberikan informasi yang lebih lengkap melalui indepth interview dan FGD dengan para Pakar dan Praktisi. Adapun obyek penelitian ini adalah LKMS berbasis grameen yang tersebar di JABODETABEK.

Key word: Grameen Syariah, LKMS, DEKOMPOSISI ANP

\section{PENDAHULUAN}

\section{Latar Belakang Penelitian}

Lembaga Keuangan Mikro (LKM) berbasis grameen merupakan salah satu fenomena istimewa yang bahkan sampai mengantarkan pencetusnya yaitu Muhammad Yunus dari Bangladesh menjadi penerima nobel perdamaian pada tahun 2006. Kesuksesan LKMS berbasis grameen dalam mengentaskan kemiskinan menjadikan model tersebut banyak di replikasi di berbagai belahan dunia seperti Filipina, Malaysia, dan termasuk juga Indonesia. Dalam replikasinya di Indonesia LKM berbasis grameen ini mengalami berbagai modifikasi dan penyesuaian(Baga dkk, 2017). Yang menjadi menarik adalah ternyata sebagian besar LKM berbasis grameen yang dapat terus bertumbuh dan konsisten dalam memberdayakan fakir miskin di Indonesia adalah model grameen syariah (Junaedi dkk, 2012).

Akan tetapi kenyataan yang terjadi di lapangan adalah banyak sekali terdapat berbagai hambatan dan permasalahan yang dihadapi lkms berbasis grameen ini (Afriadi \& Findi, 2018). Dari sisi bidang akuntansi hal tersebut muncul tidak hanya dari proses pencatatan transaksi hingga pelaporan keuangan saja, melainkan juga muncul pada sisi sistem, audit, hingga pada sisi perpajakan. Dari sisi operasional, permasalahan yang muncul yaitu mulai dari sumber daya manusia, sistem tata kelola lembaga yang masih asal "berjalan saja", hingga terbatasnya modal (Irawan dkk, 2013). Terkait dengan permasalahan modal 
banyak LKMS yang menyatakan pesimis mampu mengatasi kebutuhan likuiditas secara mandiri (Sakti, 2013).

Mengingat perannya yang sangat besar dalam mendorong usaha mikro, keberadaan lembaga keuangan mikro syariah (LKMS) berbasis grameen mesti dijaga dan ditingkatkan kinerjanya. Salahsatu langkah yang perlu dilakukan adalah mendiagnosis permasalahan-permasalahan pada lembaga keuangan mikro syariah (LKMS) berbasis grameen . Sedangkan pembahasan tentang hal ini masih sangat langka, bahkan penulis sampai saat ini belum menemukan tulisan yang membahas secara khusus permasalahan-permasalahan lembaga keuangan mikro syariah (LKMS) berbasis grameen. Oleh karena itulah penulis merasa perlu untuk menganalisa apa saja permasalahan-permasalahan lembaga keuangan mikro syariah (LKMS) berbasis grameen. Dengan diketahuinya permasalahan lembaga keuangan mikro syariah (LKMS) berbasis grameen maka lembaga keuangan mikro syariah (LKMS) berbasis grameen akan lebih berkembang dengan pesat, karena permasalahan-permasalahan yang ada sudah terpetakan dengan baik. Pada akhirnya, penyelesaian permasalahan akan lebih terorganisir dan lembaga keuangan mikro syariah (LKMS) berbasis grameen dapat memberikan kontribusi yang lebih besar kepada perekonomian dan kesejahteraan umat Indonesia.

\section{METODE RISET}

Penelitian ini merupakan penelitian analisis kualitatif yang berusaha untuk menangkap suatu nilai atau pandangan yang diwakili para pakar dan praktisi LKMS berbasis grameen tentang analisa benefit, opportunity, cost dan risk dari berbagai alternatif bantuan likuiditas kepada LKMS. Untuk mendapatkan alternatif terbaik maka diperlukan dekomposisi permasalahan dan pembobotan prioritas yang terukur dari berbagai alternatif kemungkinan yang ada. Oleh sebab itu, metodologi yang tepat untuk penelitian ini adalah dengan ANP BOCR. Metode ANP BOCR cocok digunakan karena mempunyai tiga fungsi utama yang sangat cocok menjawab rumusan masalah dari penelitian ini. Tiga fungsi utama tersebut yaitu(Ascarya, 2005):

1) Menstruktur kompleksitas.

2) Pengukuran ke dalam skala rasio.

3) Sintesis.

Analytic Network Process atau ANP adalah teori matematis yang memungkinkan kita menghadapi faktor-faktor dependence serta feedbacknya secara sistematik. Dalam bahasa lain, ANP merupakan satu dari metode Multiple Criteria Decision Making (MCDM) (Saaty, 2005). Survei, wawancara dan studi literatur merupakan sumber data untuk penyusunan kerangka model ANP. Kerangka ANP yang telah disusun baru dapat diselesaikan setelah tersedia data maupun informasi preferensi/tanggapan/pendapat yang diwakili oleh para pakar/ praktisi ekonomi Islam tentang permasalahan yang akan diteliti.

Untuk memperoleh data preferensi tersebut, digunakan (kuesioner/ wawancara langsung) kepada para pakar dan praktisi. Pengumpulan data ini dititik beratkan bagi kalangan praktisi LKMS maupun praktisi arisan majelis ta'lim 
untuk mendapatkan data-data yang diperlukan untuk analisa kualitatif dalam kerangka analisis yang akan digunakan. Jenis data yang digunakan dalam penelitian ini adalah data primer.

Metodologi ANP memiliki banyak keunggulan jika dibandingkan dengan AHP. beberapa keunggulan tersebut meliputi perbandingan yang lebih objektif, prediksi yang lebih akurat, dan hasil yang lebih stabil dan kuat. ANP lebih umum daripada AHP yang digunakan dalam analisis keputusan multi-kriteria. Struktur AHP adalah bagaimana menentukan keputusan dalam bentuk tingkat hierarki, sedangkan ANP menggunakan pendekatan jaringan tanpa harus menetapkan tingkat seperti dalam hierarki. (Saaty, 2006)

Untuk menyelesaikan penelitian menggunakan metodologi ANP, ada beberapa langkah yang harus diambil, dan di antaranya adalah (Ascarya, 2009):

1. Melakukan studi literatur dan wawancara mendalam tentang masalah yang akan diteliti kepada para ahli dan praktisi yang memahami dan menguasai masalah secara komprehensif;

2. Penguraian atau dekomposisi permasalahan untuk mengidentifikasi, menganalisis, dan menyusun kompleksitas masalah ke dalam jaringan ANP

3. Menyusun pair-wise comparison (kuesioner perbandingan) sesuai dengan jaringan ANP yang telah tersusun;

4. Melakukan wawancara kembali kepada para ahli dan praktisi yang dianggap paling kompeten dengan cara mengisi kuesioner perbandingan;

5. Menyintesis dan mengolah data (hasil survei dalam bentuk mengisi kuesioner) menggunakan perangkat lunak ANP yaitu superdecisions; dan

6. Analisis hasil dan merumuskan rekomendasi strategi.

Ketujuh langkah di atas tergambar dalam gambar berikut: 


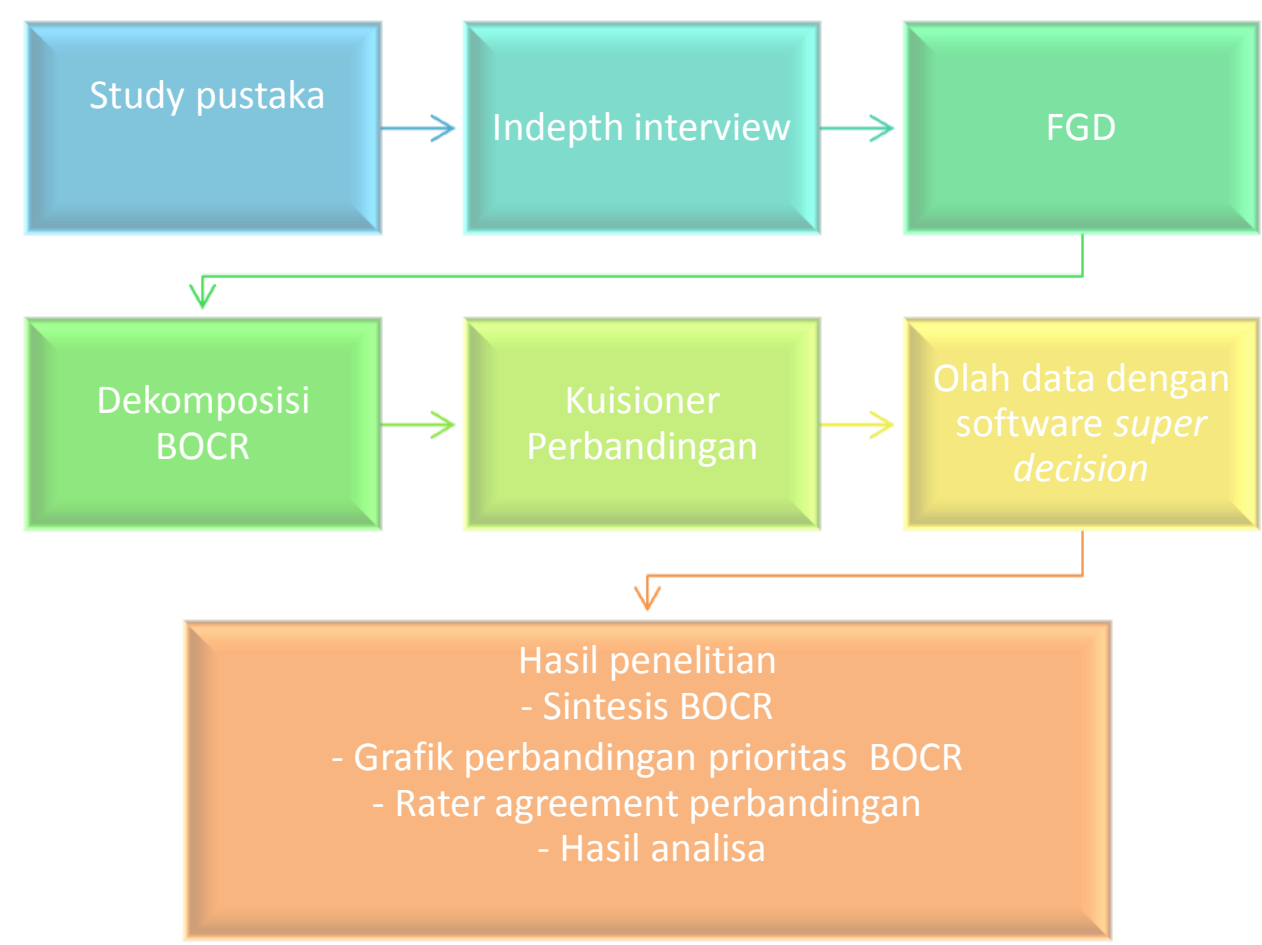

\section{ANALISIS DATA DAN PEMBAHASAN}

\section{Identifikasi dan Dekomposisi Masalah}

Dari hasil studi literatur dan beberapa pendapat yang telah dikumpulkan dari para praktisi dan akademisi melalui indepth interview (wawancara secara mendalam) pada penelitian awal (preliminiery research), ada beberapa permasalahan pengembangan LKMS dari sisi regulasi dan institusi antara lain sebagai berikut :

\section{Belum Adanya Regulasi Mengenai Pembatasan Persaingan}

Pasar keuangan mikro secara umum dianggap sangat menarik. Hal tersebut dikarenakan tingkat imbal bagi hasil yang relatif tinggi. Ada empat jenis lembaga keuangan yang bersaing di pasar keuangan mikro; 1) Bank umum dan lembaga keuangan non bank yang memberikan salah satu layanan keuangan mikro; 2) Bank umum dan lembaga keuangan non bank yang khusus hanya memberikan layanan keuangan mikro; 3) koperasi; dan 4) lembaga keuangan mikro syariah (LKMS) berbasis grameen (Jansson et al., 2004). Di Indonesia, BPRS bisa dikategorikan pada kelompok yang kedua. Dapat dilihat bahwa lembaga keuangan mikro syariah (LKMS) berbasis grameen menghadapi level persaingan yang tidak seimbang mengingat masing-masing lembaga, terutama bank umum memiliki skala bisnis yang jauh lebih besar sehingga cost of fund nya bisa lebih kecil (Masyita \& Ahmed, 2011). 
Pada studi mengenai layanan keuangan mikro yang dilakukan oleh ADB pada tahun 2003, di tiga regional unit BRI terbukti unggul dengan cakupan layanan yang luas dan kinerja yang baik. Di dua regional lainnya ditemukan bahwa lembaga keuangan mikro syariah (LKMS) berbasis grameen secara umum mengalami kegagalan, sementara di regional yang lain lembaga keuangan mikro syariah (LKMS) berbasis grameen menunjukkan harapan pengembangan setelah dilakukan restrukturisasi dan diberikan suntikan modal. Studi yang dilakukan oleh Sakti (2013) menunjukkan bahwa salah satu kendala utama yang dihadapi oleh pengurus dalam mengembangkan lembaga keuangan mikro syariah (LKMS) berbasis grameen adalah masalah persaingan. ${ }^{17}$ Kinerja lembaga keuangan mikro syariah (LKMS) berbasis grameen diantara persaingan bisnis perbankan merupakan salah satu faktor yang mempengaruhi profesionalisme praktisi lembaga keuangan mikro syariah (LKMS) berbasis grameen (Karsidi et al, 2011).

\section{Belum Adanya Regulasi Penunjang}

Hamzah et al (2013) pada penelitiannya menyimpulkan bahwa masalah eksternal yang menempati prioritas tertinggi pada pengembangan LKMS adalah tidak adanya regulasi yang secara spesifik mengatur tentang LKMS. Padahal, LKMS membutuhkan pengaturan dan pengawasan yang efektif. Untuk menghindari terjadinya kerugian pada masyarakat sebagai nasabah, seharusnya hanya LKMS yang sehat dan terawasi dengan baik yang dibolehkan untuk mengumpulkan dana dari selain anggota (Seibel \& Agung, 2008).

Lembaga keuangan mikro syariah (LKMS) berbasis grameen sebagai lembaga keuangan yang relatif dekat dan dengan demikian bergantung pada kepercayaan masyarakat, harus dijalankan dengan penuh kehati-hatian karena memiliki risiko yang tinggi (Imaniyati, 2004). Tidak adanya sistem penjaminan dana nasabah bagi lembaga keuangan mikro syariah (LKMS) berbasis grameen menjadi kendala dalam mengoptimalkan penghimpunan (Hascaryani et al., 2011). Hal tersebut kemudian mengakibatkan jangkauan pelayanan LKM masih belum mampu menjangkau secara luas. Salah satu institusi yang dibutuhkan untuk mengatasi hal tersebut adalah lembaga penjamin untuk menjamin kredit LKM atau menjamin pembiayaan pada LKMS (Soetrisno, 2005). Kusmuljono (2009) juga menyarankan agar didirikan Apex lembaga keuangan mikro syariah (LKMS) berbasis grameen yang memayungi lembaga keuangan mikro.

\section{Belum Adanya Standarisasi Operasional}

Lembaga keuangan mikro syariah (LKMS) berbasis grameen memiliki risiko likuiditas yang sangat rentan mengingat kebanyakan anggota atau nasabahnya dominan dari sektor usaha mikro-kecil. Pada musim-musim tertentu misalnya setiap tahun ajaran baru atau hari besar keagamaan seperti Idul Fitri dan Idul Adha, risiko likuiditas menjadi meningkat mengingat banyak anggota dan nasabah yang menarik dana mereka hampir secara bersamaan (Sakti, 2013).

\footnotetext{
${ }^{17} 12,83 \%$ responden pada penelitian ini menyatakan hal tersebut. Sampel diambil dari survey pada populasi BMT yang ada di wilayah provinsi Jawa Barat, Jawa Tengah dan Jawa Timur
} 
Standar analisis pembiayaan dan manajemen resiko penting untuk diadakan. Pembiayaan bermasalah bermula dari kesalahan praktek uji kelayakan usaha (Karsidi, 2011). Faktor kesalahan proyeksi operasional terbukti cukup menonjol menjadi penyebab kesulitan likuiditas lembaga keuangan mikro syariah (LKMS) berbasis grameen (Sakti, 2013). Faktor kejujuran dari nasabah dan partner kerja lembaga keuangan mikro syariah (LKMS) berbasis grameen juga menjadi salah satu kendala, terutama pada produk pembiayaan yang berbasiskan bagi hasil; seperti pembiayaan mudharabah dan musyarakah (Mustamir \& Mawardi, 2006).

Salah satu keunggulan lembaga keuangan mikro syariah (LKMS) berbasis grameen adalah kedekatan dengan anggotanya. Untuk menjaga dan memelihara sekaligus meningkatkan kemampuan anggota juga sekaligus memastikan susatinabilitas lembaga keuangan mikro syariah (LKMS) berbasis grameen, diperlukan juga standar dalam pendampingan dan pembinaan nasabah ${ }^{18}$. Lokasi nasabah yang tersebar menambah beban biaya yang dibutuhkan (Sakti, 2013).

Perbedaan mendasar antara lembaga keuangan mikro syariah (LKMS) berbasis grameen dengan LKM lainnya terletak pada layanannya yang sesuai dengan prinsip syariah. Dengan demikian, yang seharusnya menjadi tolok ukur profesionalisme bagi para praktisi lembaga keuangan mikro syariah (LKMS) berbasis grameen adalah dalam hal penguasaan konsep keuangan syari'ah, baik secara teoritis maupun praktis (Karsidi et al 2011). Penelitian Karsidi et al (2011) menemukan bahwa terdapat praktisi yang belum menguasai konsep keuangan syariah dengan baik. Penelitian Kholim (2004) menyimpulkan bahwa salah satu yang menghambat operasional adalah belum difahaminya konsep-konsep ekonomi dan keuangan syariah. Dengan demikian, disusunnya standar kepatuhan syariah juga merupakan salah satu kebutuhan.

\section{Belum Memadainya Bantuan Operasional}

Salah satu kendala utama yang dihadapi oleh pengurus dalam pengelolaan lembaga keuangan mikro syariah (LKMS) berbasis grameen adalah masalah permodalan $^{19}$ (Sakti, 2013). Penelitian lain seperti Soetrisno (2005) juga menyatakan hal yang sama. Pembinaan Managerial dan Pengembangan SdM juga merupakan masalah yang banyak dihadapi pada lembaga keuangan mikro syariah (LKMS) berbasis grameen. Hal tersebut seperti juga disimpulkan dari penelitian Hamzah et al (2013) yang menyatakan bahwa masalah SdM merupakan masalah internal yang menduduki prioritas tertinggi. Penelitian Sakti (2013) dan Soetrisno (2005) juga salah satunya menyimpulkan bahwa kendala yang juga cukup menonjol dihadapi pengurus lembaga keuangan mikro syariah (LKMS) berbasis

\footnotetext{
${ }^{18}$ Pada survey yang dilakukan oleh Sakti (2013), bentuk-bentuk pembinaan yang dilakukan umumnya berupa kunjungan berkala kepada anggota, khususnya nasabah pembiayaan. Selain itu bentuk pembinaan anggota bisa berupa pertemuan anggota, sosialisasi produk dan pemberian jasa konsultasi bisnis. Bentuk pembinaan tersebut dilakukan secara beragam.

${ }^{19}$ Pada penelitian Sakti, 56,15\% responden menyatakan hal tersebut
} 
grameen adalah masalah kompetensi SDM ${ }^{20}$. Selain itu, masalah internal lainnya yang dihadapi oleh lembaga keuangan mikro syariah (LKMS) berbasis grameen adalah kurangnya kemampuan manajerial (Soetrisno, 2005), kurangnya fasilitas TI, dan kurangnya inovasi produk (Hamzah, 2013).

Dari penjelasan dekomposisi masalah di atas berikut dirangkum dalam tabel mengenai literatur dari masing-masing elemen.

TABEL 3.1 Sumber Literatur Elemen Dan Cluster

\begin{tabular}{|c|l|l|}
\hline No & \multicolumn{1}{|c|}{ Nama Elemen } & \multicolumn{1}{c|}{ Literatur } \\
\hline 1 & $\begin{array}{l}\text { Regulasi Pembatasan } \\
\text { Persaingan (Lintas }\end{array}$ & $\begin{array}{l}\text { Jansson et al., 2004, Masyita \& Ahmed, 2011, } \\
\text { Sakti, 2011, Karsidi et al, 2011, }\end{array}$ \\
\hline 2 & Regulasi Penunjang & $\begin{array}{l}\text { Hamzah et al 2013, Seibel \& Agung, 2008, } \\
\text { Imaniyati, 2004, Hascaryani et al., 2011, Sakti, } \\
\text { 2011, }\end{array}$ \\
\hline 3 & Standar Operasional & $\begin{array}{l}\text { Sakti, 2011, Karsidi, 2011, Mustamir \& Mawardi, } \\
\text { 2006, Kholim, 2004, Seibel \& Agung, 2008, }\end{array}$ \\
\hline 4 & Bantuan Operasional & Karsidi, 2011, Sakti, 2011, Hmzah et al 2013, \\
\hline 5 & $\begin{array}{l}\text { Jumlah Plafon } \\
\text { Pembiayaan }\end{array}$ & Abdullah Yazid, Sugiyanto \\
\hline 6 & Omset nasabah & $\begin{array}{l}\text { UU No 20 Tahun 2008 tentang UMKM, Abdullah } \\
\text { Yazid }\end{array}$ \\
\hline 7 & S-Coverage & Sakti (2011) \\
\hline 8 & Penjamin Simpanan & (Hascaryani et al., 2011) (Imaniyati, 2004) (Sakti, \\
2011) Kusmuljono (2009)
\end{tabular}

${ }^{20}$ Pada penelitian Sakti, $15,24 \%$ responden menyatakan hal tersebut 


\subsection{Kerangka Konseptual}

Kerangka konseptual dari penelitian ini dapat dilihat pada gambar di halaman berikut ini.

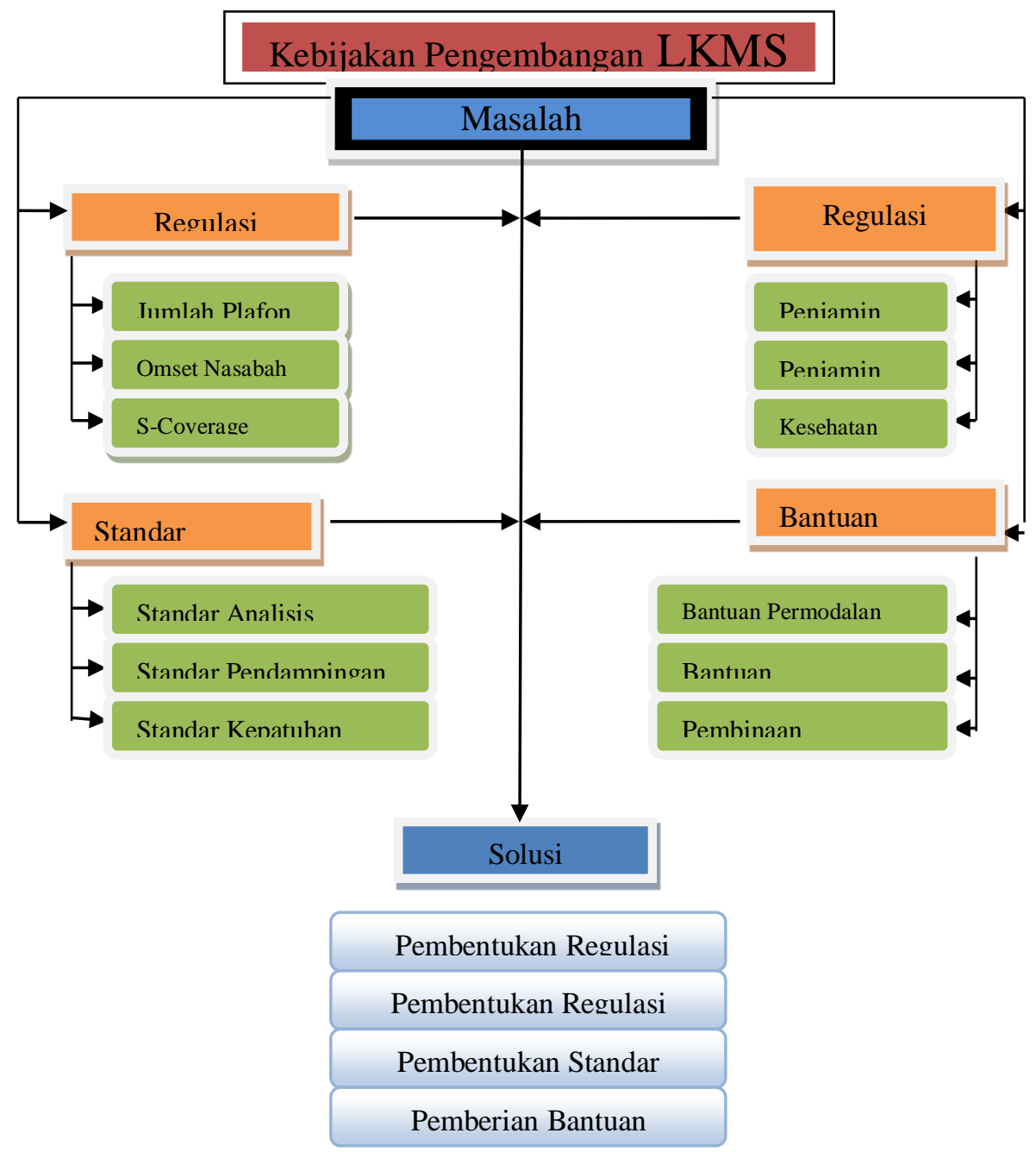

Gambar 3.1 Kerangka Konseptual Penelitian 
Vol.2, No. 1, Jan. 2019

\section{Solusi Permasalahan LKMS berbasis grameen}

Dari berbagai permasalahan yang didapatkan dari hasil penelitian berikut beberapa solusi yang ditawarkan oleh para akademisi dan praktisi.

\section{Solusi Regulasi Mengenai Pembatasan Persaingan}

Pada permasalahan regulasi mengenai pembatasan persaingan, maka solusi yang bisa ditawarkan adalah disusun dan diterbitkannya peraturan yang mengatur pembagian pangsa pasar antara lembaga keuangan mikro syariah (LKMS) berbasis grameen dengan BUS yang mempunyai program layanan mikro. Hal ini senada dengan yang diungkapkan oleh Sakti (2013) memastikan bahwa layanan lembaga keuangan mikro syariah (LKMS) berbasis grameen dapat menjangkau masyarakat juga penting, mengingat faktor umum yang utama mendukung perkembangan lembaga keuangan mikro syariah (LKMS) berbasis grameen adalah pelayanan lembaga keuangan mikro syariah (LKMS) berbasis grameen yang terjangkau bagi masyarakat (anggota). tapi koperasi dan ojk belum ketemu. Harus duduk bersama antara kementrian koperasi dan OJK, menentukan bagaimana wilayah OJK dan wilayah koperasi. Pemerintah harus berfikir jangka panjang, membangun fondasi ekonomi yang betul-betul kuat, LKM yang dimiliki anak bangsa harus di suport, filosofi inilah yang harus difahami. Lembaga keuangan mikro asing masuk hanya kejar target, kredit macet, eksekusi jaminan UKM mati, itu adalah kapitalisasi. ${ }^{21}$

\section{Solusi Belum Adanya Regulasi Penunjang}

Salah satu upaya yang dapat dilakukan untuk mencoba mengatasi masalah permodalan adalah melakukan linkage dengan bank syariah. Akan tetapi, selama ini linkage dengan bank syariah masih menemui kendala, salah satunya mengenai masalah belum tersedianya informasi yang relevan terkait tingkat kesehatan lembaga keuangan mikro syariah (LKMS) berbasis grameen. (Sakti, 2013). Sebetulnya, pengawasan ini bukannya tidak dilakukan sama sekali. Pada beberapa survey yang dilakukan ${ }^{22}$, sebagian responden dari para pengurus lembaga keuangan mikro syariah (LKMS) berbasis grameen menyatakan ada pengawasan reguler yang dilakukan. Hanya saja, ditemukan bahwa pengawasan ini belum berjalan secara rutin dan merata di semua LKMS dan ketika dilakukan pun indikator atau rasio keuangan atau manajemen yang dijadikan ukuran tingkat kesehatan masih belum seragam ${ }^{23}$. Pengawasan misalnya berjalan secara kondisional pada saat diperlukan keterangan mengenai kondisi lembaga keuangan mikro syariah (LKMS) berbasis grameen dalam rangka program-program bantuan permodalan, baik dari pemerintah ${ }^{24}$ maupun dari pihak swasta (Sakti, 2013).

\footnotetext{
${ }^{21}$ Sesuai dengan pendapat Abdullah yazid dalam indepth interview hari rabu tanggal 06 November 2013 pukul 12.15-13.15

${ }^{22}$ Misalnya oleh Seibel dan Agung (2008) dan Sakti (2013)

${ }^{23}$ Biasanya ukuran yang digunakan minimal adalah Non Performing Financing (NPF), Return on Asset ( ROA) dan Return on Equity(ROE)

${ }^{24}$ Misalnya, pada tahun 1998, pemerintah melalui beberapa departemen terkait, menggulirkan beberapa program pengembangan lembaga keuangan mikro dalam rangka mengantisipasi penurunan kinerja ekonomi dan peningkatan pengangguran akibat krisis
} 
Di antara lembaga yang telah menjalankan fungsi pengawasan dan penilaian kesehatan adalah Dinas Koperasi, Asosiasi lembaga keuangan mikro syariah (LKMS) berbasis grameen seperti Puskopsyah, Lembaga Pembina lembaga keuangan mikro syariah (LKMS) berbasis grameen (seperti PINBUK, BMT Center dan Inkopsyah) dan RAT. Belum ada satu lembaga yang khusus yang memiliki fungsi pengawasan yang formal. Untuk perkembangan industri LKMS yang lebih baik, diperlukan pembenahan dalam tata kelola industri secara makro. Selain itu, diharapkan ada lembaga penjamin mikro atau semacam lembaga asuransi yang dapat melakukan mitigasi resiko baik bagi deposan lembaga keuangan mikro syariah (LKMS) berbasis grameen maupun L lembaga keuangan mikro syariah (LKMS) berbasis grameen itu sendiri (Sakti, 2013). ${ }^{25}$ Sejauh ini, upaya ke arah sana telah dilakukan. Telah disepakati adanya kerja sama antara Asosiasi Kredit Indonesia (Askrindo) ${ }^{26}$ Syariah dan Asosiasi Baitulmaal wat Tamwil Se-Indonesia (Absindo) ${ }^{27}$.

\section{Solusi Belum Adanya Standarisasi Operasional}

Secara umum, pengaturan, pelaporan, dan pengawasan belum berjalan secara efektif (Seibel \& Agung, 2008). Karena tidak adanya standar yang baku, laporan yang diberikan tidak seragam, terlebih karena tidak ada sanksi, ada juga yang tidak melaporkan kondisi keuangannya. Dengan tidak adanya proses auditing eksternal, tidak ada pula sistem punishment bagi LKMS yang tidak mengumpulkan laporan keuangan. Sehingga, tidak ada pula prosedur standar untuk koperasi yang memutuskan untuk tidak melanjutkan usahanya (Seibel \& Agung, 2008). Beberapa penelitian tentang lembaga keuangan mikro syariah (LKMS) berbasis grameen juga memberikan rekomendasi untuk diadakannya pelatihan yang menyeluruh, tidak hanya pada operasional lembaga keuangan mikro syariah (LKMS) berbasis grameen, tetapi juga pada pendampingan dan pembinaan nasabah dan pada konsep keuangan syariah seperti penelitian Kholim (2004) dan Karsidi (2011).

\section{Solusi Belum Memadainya Bantuan Operasional}

Dengan berbagai keterbatasan, telah dilakukan berbagai pelatihan yang menyangkut kemampuan operasional lembaga keuangan mikro syariah (LKMS) berbasis grameen. Akan tetapi, hal tersebut belum dilakukan secara merata. Pelatihan SDM lembaga keuangan mikro syariah (LKMS) berbasis grameen pun masih berkonsentrasi pada pelatihan yang bersifat dasar (Sakti, 2011) ${ }^{28}$. Mengingat ketersediaan dana yang terbatas, dibutuhkan bantuan dari pemerintah agar semua LKMS dapat menyelenggarakan berbagai program pelatihan yang dibutuhkan untuk meningkatkan kapasitas SDM terutama dalam hal operasional lembaga

\footnotetext{
${ }^{25}$ Lihat juga Soetrisno, 2005.

${ }^{26}$ Askrindo Merupakan Badan Usaha Milik Negara (BUMN) yang didirikan pada tahun 1971, memiliki anak perusahaan Askrindo syariah yang beroperasi sejak Februari 2013

${ }^{27}$ Kesepakatan kerjasama tersebut dilakukan pada tanggal 20 Mei 2013.

${ }^{28}$ Dalam survey yang dilakukan Sakti (2013), diketahui bahwa jenis pelatihan yang banyak dilakukan oleh BMT adalah pelatihan tentang operasional BMT, pelatihan akuntansi, dan pelatihan pemasaran BMT .
} 
keuangan mikro syariah (LKMS) berbasis grameen, dan penguasaan teknologi informasi untuk memermudah pengelolaan. Terselesaikannya masalah layanan yang belum terkomputerisasi diharapkan dapat meningkatkan daya saing lembaga keuangan mikro syariah (LKMS) berbasis grameen (Karsidi, 2011).

Jika ditelaah lebih jauh, fungsi-fungsi krusial dalam industri keuangan mikro syariah khususnya yang dilaksanakan oleh lembaga keuangan mikro syariah (LKMS) berbasis grameen (KJKS) sudah ada, seperti fungsi regulasi dan supervisi, advokasi dan penyedia likuiditas, baik untuk liquidity management maupun untuk lender of the last resort. Fungsi pengaturan dan perizinan dilakukan oleh Kementeriaan Koperasi dan UMKM. Tetapi, fungsi pengawasan pelaksanaannya dilakukan oleh Kantor Dinas Koperasi yang ada di bawah koordinasi Pemerintah Daerah (Pemda), baik di tingkat provinsi maupun kabupaten atau kotamadya. Terpisahnya dua entitas lembaga yang memiliki fungsi otoritas menjadi tantangan tersendiri khususnya dalam hal sinkronisasi kebijakan dan efektifitas pelaksanaan kebijakan.

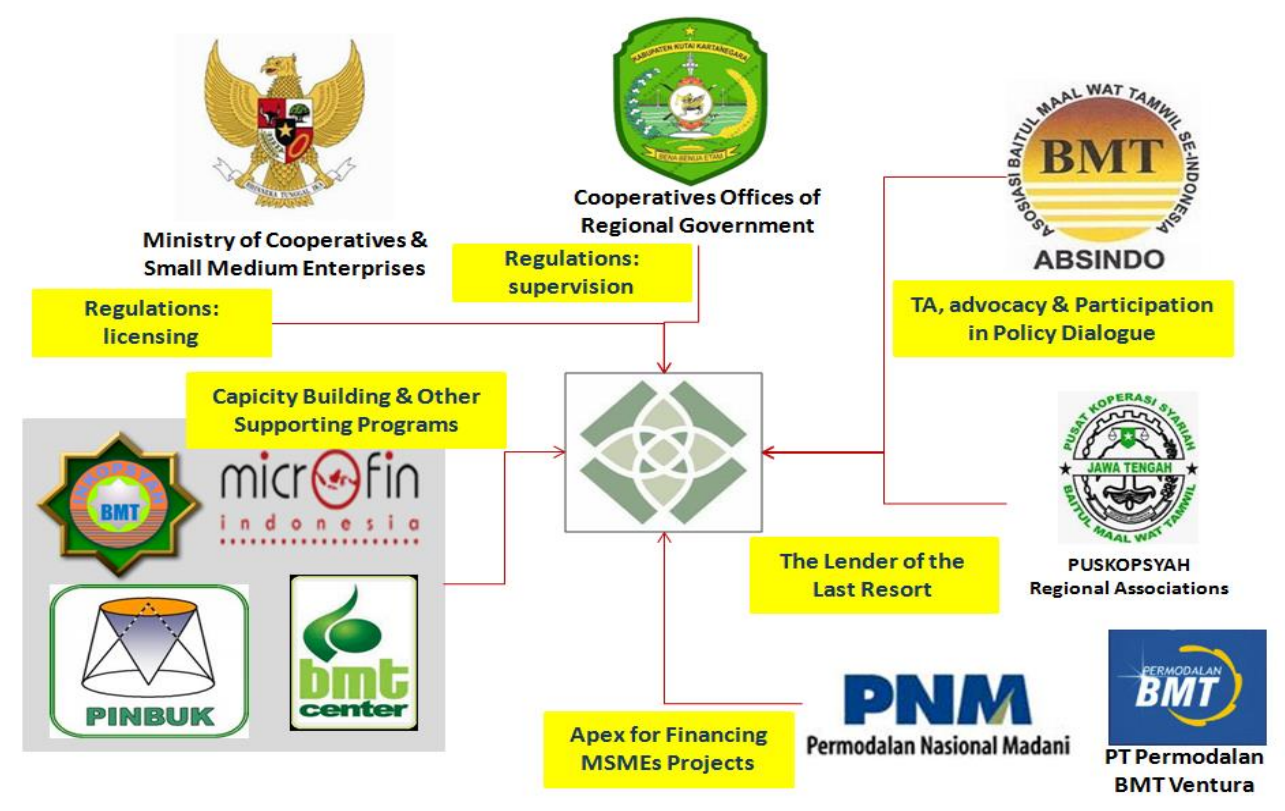

Gambar 3.2 Hubungan antar lembaga pada LKMS

Sumber: Sakti, 2013

Beberapa Lembaga Pembina lembaga keuangan mikro syariah (LKMS) berbasis grameen lainnya berperan sebagai pendamping dan konsultan yang menyediakan pelayanan capacity building dan pengembangan fasilitas TI atau membantu penyaluran dana bantuan dari lembaga donor, diantaranya Pusat Inkubasi Bisnis Usaha Kecil (PINBUK) ${ }^{29}$, Induk Koperasi Syariah $(\text { INKOPSYAH })^{30}$, MICROFIN Indonesia ${ }^{31}$, BMT CENTER ${ }^{32}$, Asosiasi BMT Se-

\footnotetext{
${ }^{29}$ didirikan oleh ICMI pada tanggal 13 Maret 1995

${ }^{30}$ pendiriannya digagas oleh PINBUK pada tanggal 7 Juli 1998

${ }^{31}$ berdiri sejak 30 November 2001

${ }^{32}$ berdiri pada tanggal 14 Juni 2005 dengan diprakarsai oleh Dompet Dhuafa
} 
Indonesia (ABSINDO) ${ }^{33}$; Pusat Koperasi Syariah (PUSKOPSYAH) ${ }^{34}$. Selain itu, ada juga lembaga APEX yang memberikan fasilitas likuiditas bagi lembaga keuangan mikro syariah (LKMS) berbasis grameen seperti PT. Permodalan Nasional Madani (PNM) Persero dan Permodalan BMT Ventura. (Sakti, 2013). Jika digambarkan, hubungan antar berbagai lembaga ini adalah sebagaimana pada gambar 5.14 di atas.

Berdasarkan survey yang dilakukan Sakti (2013), lembaga keuangan mikro syariah (LKMS) berbasis grameen berharap pemerintahlah yang dapat mengambil peran sebagai lender of last resort bagi kebutuhan likuiditas lembaga keuangan mikro syariah (LKMS) berbasis grameen. Sumber lain yang diharapkan adalah linkage dengan lembaga keuangan mikro syariah (LKMS) melalui asosiasi lokal dan linkage dengan bank syariah.

Salah satu solusi yang dapat ditawarkan untuk mengatasi masalah permodalan dan pembinaan SDM dan IT adalah linkage dengan perbankan syariah. Ada tiga skema linkage yang biasanya digunakan oleh bank syariah, induk lembaga keuangan mikro syariah (LKMS) berbasis grameen , pemerintah daerah, atau lembaga keuangan lain; yaitu skema channeling, executing atau joint financing. Perlu dibuat kebijakan yang jelas dan praktis untuk dapat mengoptimalkan hal tersebut.

\section{KESIMPULAN DAN SARAN}

\section{Kesimpulan}

Berdasarkan pembahasan dan analisa permasalahan pengembangan LKMS dari sisi regulasi dan institusi, berikut dapat ditarik beberapa kesimpulan mengenai pembahasan ini, diantaranya adalah:

1. Berdasarkan hasil penelitian (dekomposisi masalah) menunjukkan bahwa permasalahan pengembangan LKMS dari sisi regulasi dan institusi dibagi menjadi 4 cluster utama, yaitu permasalahan tidak adanya regulasi pembatas persaingan (lintas LK), tidak adanya regulasi lembaga penunjang, tidak adanya standar operasional dan minimnya bantuan operasional. Cluster permasalahan tidak adanya regulasi pembatasan persaingan (lintas LK) terdiri dari 3 elemen yaitu pembatasan persaingan melalui plafon, omset dan S-coverage. Cluster permasalahan tidak adanya regulasi penunjang juga terdiri dari 3 elemen yaitu penjamin simpanan, penilai kesehatan dan penjamin kredit. Cluster permasalahan ketiga yaitu tidak adanya standar operasional dengan tiga elemen yaitu stndar analisis pembiayaan dan manajemen risiko, standar kepatuhan syariah dan standar pendampingan dan pembinaan. Dan cluster permasalahan terakhir yaitu minimnya bantuan operasional dengan tiga elemen yaitu bantuan

\footnotetext{
${ }^{33}$ berdiri pada tanggal 4 Desember 2005 sebagai hasil dari Kongres LEMBAGA KEUANGAN MIKRO SYARIAH (LKMS) BERBASIS GRAMEEN Nasional

${ }^{34}$ merupakan asosiasi LEMBAGA KEUANGAN MIKRO SYARIAH (LKMS) BERBASIS GRAMEEN yang ada di daerah berfungsi sebagai lembaga lender of last resort bagi LEMBAGA KEUANGAN MIKRO SYARIAH (LKMS) BERBASIS GRAMEEN
} 
pengembangan SDM, bantuan permodalan dan bantuan teknologi informasi.

2. Permasalahan tidak adanya regulasi penunjang menjadi masalah utama dengan angka prioritas $(0,31)$, kemudian diikuti permasalahan tidak adanya standar operasional $(0,28)$, tidak adanya standar operasional $(0,27)$ dan terakhir minimnya bantuan operasional $(0,14)$

3. Pada cluster tidak adanya regulasi pembatasan persaingan, Pembatasan persaingan melalui plafon pembiayaan adalah prioritas utama dengan nilai prioritas 0,39 , diikuti dengan pembatasan persaingan melalui omset dengan nilai prioritas 0,37 dan terakhir pembatasan persaingan melalui Scoverage 0,24 .

4. Pada cluster tidak adanya regulasi penunjang, regulasi penunjang melalui penilaian kesehatan menjadi prioritas utama denan nilai prioritas 0,45 . Di peringkat prioritas ke dua dengan selisih yang cukup jauh yaitu regulasi penjamin simpanan dengan nilai prioritas 0,29 dan terakhir yaitu regulasi penjamin kredit dengan nilai prioritas 0,26.

5. Pada cluster tidak adanya standar operasional, masalah tidak adanya standar kepatuhan syariah menjadi prioritas utama denan nilai prioritas 0,39 . Di peringkat prioritas ke dua dengan selisih yang tidak jauh yaitu masalah tidak adanya standar analisis pembiayaan dan manajemen risiko dengan nilai prioritas 0,35 dan terakhir yaitu regulasi penjamin kredit dengan nilai prioritas 0,26 .

6. Pada cluster minimnya bantuan operasional, masalah minimnya Bantuan Pemberdayaan Sumberdaya Manusia menjadi prioritas utama dengan nilai prioritas 0,39. Di peringkat prioritas ke dua dan ketiga dengan selisih yang sangat tipis yaitu masalah yaitu masalah minimnya Bantuan Teknologi Informasi dengan nilai prioritas 0,27 dan urutan prioritas ketiga yaitu terbatasnya bantuan permodalan dengan nilai prioritas 0,27 .

7. Terakhir yaitu cluster solusi permasalahan, hasil dari penelitian pada cluster ini menunjukkan bahwa pembentukan standar operasional menjadi prioritas pertama dengan skala prioritas 0,31 , kemudian diikuti pembentukan regulasi persaingan 0,24 , pembentukan regulasi penunjang 0,23 dan terakhir pemberian bantuan operasional Secara keseluruhan dapat dilihat bahwa selisih nilai prioritas rata-rata adalah kecil, hal itu menandakan bahwa semua solusi yang disebutkan memiliki nilai prioritas yang hampir sama untuk segera dilaksanakan.

\subsection{Saran}

Berdasarkan hasil pembahasan, ada beberapa saran yang dapat penulis rekomendasikan, diantaranya adalah:

1. Pemerintah sebaiknya segera membentuk standar operasional karena pembentukan standar operasional mendesak untuk segera dilaksanakan. Praktisi dan akademisi sepakat bahwa pembentukan standar operasional menjadi prioritas pertama. Kemudian dilanjutkan dengan pelaksanaan solusi lainya yang telah disebutkan di atas. 
2. Untuk penelitian selanjutnya, diharapkan dapat memperluas penelitian dengan menambah responden yang mewakili dari pihak perbankan dan regulator. Hal ini belum dapat dilakukan oleh peneliti karena keterbatasan waktu dan tenaga tim peneliti.

\section{DAFTAR PUSTAKA}

Afriadi, Fiqih dan Findi, Muhammad. (2013). Solusi Peningkatan Sumberdaya Manusia Pada Baytul Maal wat Tamwil (BMT ) di Indonesia Melalui Pendekatan Analytic Network Process (ANP). Jurnal al-Muzara'ah, Volume I, Nomor. 2.

Antonio, Syafi'i. (2001). Bank Syariah: dari Teori ke Praktik, Jakarta: Gema Insani Press.

Ascarya. (2005). Analytic Network Process (ANP): Pendekatan baru studi kualitatif. Makalah pada seminar intern program Magister Akuntansi fakultas Ekonomi di Universitas Trisakti, Jakarta.

Asian Development Bank (ADB). (2003). Draft Report Rural Microfinance Indonesia (TA No.3810-INO).

Aziz, Amin. (2008). Panduan Pendirian LEMBAGA KEUANGAN MIKRO SYARIAH (LKMS) BERBASIS GRAMEEN . Jakarta: PKES Publishing.

Baga, Lukman Muhamad; Beik, Irfan Syauqi dan Nursyamsiah, Tita. (2017). Aplikasi Model Bisnis Microfinance Syariah Terhadap Sektor Umkm Di Indonesia. IQTISHADIA Volume 10 Nomor 2.

Hamzah, et al. (2013). Analysis Problem of Baitul Maal Wat Tamwil (BMT ) Operation in Pekanbaru Indonesia Using Analytical Network Process (ANP) Approach. International Journal of Academic Research in Business and Social Sciences, Vol. 3, No. 8.

Hascaryani, Tyas D et al. (2011). Metafora Risk and Return sebagai Dasar Pengembangan Baitul Maal wa Tamwil (lembaga keuangan mikro syariah (LKMS) berbasis grameen ) yang Mandiri. Journal of Indonesian Applied Economics Vol. 5 No. 1 Mei 2011, hal. 93-109.

Imaniyati, Neni Sri. (2004). Eksistensi BMT (Baitul Maal Wat Tamwil) sebagai Lembaga Keuangan Syariah di Indonesia. Jurnal Hukum Pro Justitia, Tahun XXII No. 4 Oktober 2004, hal. 71 - 84.

Irawan, Dedik; Affandi, Muhamad Irfan; dan Kalsum, Umi. (2013). Analisis Strategi Pengembangan Lembaga Keuangan Mikro Syariah (Lkms)Pedesaan (Studi Kasus Lembaga Keuangan Mikro Syariah (LKMS) berbasis grameen Al Hasanah Sekampung). JIIA, Volume 1 Nomor 1.

Jansson, T., et al. (2004). Principles and Pratices for Regulating and Supervising Microfinance. Washington: Inter-American Development Bank.

Junaedi, Dedi; Huda, Nurul; Wiliasih, Ranti dan Irianto, S. Gatot. (2012). Studi Komparasi Kinerja Pengembangan Usaha Agribisnis Perdesaan Syariah Dan Konvensional Di Jawa Tengah. Jurnal Agro Ekonomi. Volume 30 Nomor 2. 
Karsidi et al. (2011). Strategi Peningkatan Profesionalisme Praktisi BAITUL MAAL WAT TAMWIL (BMT ) di Kabupaten Banyumas. Performance: Vol. 14 No.2 September 2011, hal.13-34.

Kholim, Muhammad. (2004). EksistensiBaitul Maal Wat Tamwildan Permasalahan dalam Operasionalisasinya: Studi di Provinsi Jawa Tengah. Tesis di Universitas Diponegoro. Tidak diterbitkan.

Kusmuljono, Bangun Sarwito. (2009). Menciptakan Kesempatan Rakyat Berusaha: Sebuah Konsep Baru tentang Hybrid Microfinancing. Bogor: IPB Press.

Masyita, Dian dan Ahmed, Habib. (2011). Why is Growth of Islamic Microfinance Lower than Conventional? A Comparative Study of the Preferences and Perceptions of the Clients of Islamic and Conventional Microfinance Institutions' in Indonesia. Paper presented in $8^{\text {th }}$ International Conference on Islamic Economics and Finance, 19-21 December 2011, Qatar.

Mustamir dan Mawardi. (2006). Problematika Penerapan Ekonomi Islam di Baitul Maal Wat Tamwil (BMT ) Pekanbaru. Jurnal Publik \& Bisnis Vol 4. No.1, hal.27-35.

Ridwan, Muhammad. (2004). Manajemen Baitul Maal wa Tamwil (BMT ), Yogyakarta: UII Press.

Saaty, Thomas L. (2005). Theory and Applications of the Analytic Network Process, Pittsburgh: University of Pittsburgh.

Saaty dan Vargas. (2006). Decision Making with the Analytic Network Process, Pittsburgh: University of Pittsburgh.

Sakti, Ali. (2013). Pemetaan Kondisi Dan Potensi Lembaga Keuangan Mikro Syariah (LKMS) berbasis grameen : Kemitraan dalam rangka Memperluas Pasar \& Jangkauan Pelayanan Bank Syariah kepada Usaha Mikro1. Jurnal al-Muzara'ah fem ipb, Volume I, Nomor 1.

Sakti, Ali. (2013). Pemetaan Kondisi dan Potensi BMT : Kemitraan dalam rangka Memperluas Pasar dan Jangkauan Pelayanan Bank Syariah kepada Usaha Mikro. Jurnal Al Muzara'ah Vol.1 no.1 2013 hal.1-17.

Seibel, Hans Dieter., Agung, Wahyu Dwi. Islamic Microfinance in Indonesia: The Challenge of Institutional Diversity, Regulation, and Supervision. Sojourn: Journal of Social Issues in Southeast Asia Vol. 23, No. 1 April 2008, hal. 86-103.

Soetrisno, Noer. (2005). Ekonomi Rakyat Usaha Mikro dan UKM dalam Perekonomian Indonesia. Jakarta: STEKPI.

Syaflan, Meidi. (2011). Model Governance BMT : Perspektif Sejarah dan Praktisi. Yogyakarta: LOS DIY.

Undang- undang nomor 1 Tahun (2013) tentang Lembaga Keuangan Mikro (LKM).

Undang- undang nomor 17 Tahun (2012) tentang Perkoperasian.

Vogel, Frank E dan Samuel L. Hayes III. (2007). Hukum Keuangan Islam: Konsep, Teori, dan Praktik. Bandung:Nusamedia.

Wafa, Muhammad Agus dan Nasrodin. (2008). Baitul maal Wa At-Tamwil, Tugas, tidak diterbitkan. 